Perinatal autopsy

\section{Perinatal autopsy remains the "gold standard"}

\section{A Lyon}

\section{A commentary on the review by Wright and Lee}

$\mathrm{T}$ here is little doubt that a full autopsy carried out by a perinatal pathologist, and supported by the techniques described in this review, remains the best method of investigating perinatal death. The authors discuss clearly the limitations of all other techniques, which, although capable of giving much useful information, have not yet been validated adequately against the properly performed perinatal autopsy. Permission for this procedure should be sought after all pregnancy losses and neonatal deaths.

Despite its importance, neonatal autopsy rates have been falling. ${ }^{1}$ There are many reasons for this but of most concern is the possible decline in healthcare professionals' understanding of its value. Recent controversies have made asking for an autopsy soon after birth even more stressful. Many may believe that, with better investigative techniques before death, the diagnosis is already known, and therefore either do not ask for an autopsy or do not give parents complete information. Whatever we think we know, perinatal autopsy will reveal new and important information in up to $25 \%$ of cases.

In her review of parents' experiences of treatment withdrawal from infants, Hazel McHaffie interviewed parents three months and 13 months after the death of their baby. ${ }^{2}$ The babies had all been cared for in three tertiary centres in the East of Scotland and so the results reflect practice of the consultants in those units. All except one family were asked to give permission for an autopsy, and 62\% agreed. In 11 families there was initial reluctance but they were persuaded to give consent. For three of these it was reassurance that the procedure would be carried out delicately that persuaded them to agree.

The parents gave many reasons for agreeing to an autopsy, but the principal one was to obtain answers to their questions, with a desire to help others the second most common motivation. Looking at the reasons for refusing permission, the prevailing fear was a dread of the child being mutilated, coupled with a wish not to have anything else done to a baby who had already been through so much. I would argue that it is precisely because the baby has been through so much, and yet the outcome is negative, that it is not only the parents', but also the baby's, right to have these investigations carried out, to be sure we have the best chance of explaining why he/she died.

The second most common reason for refusing permission was that the parents had no unanswered questions. This suggests that whoever was seeking consent was unaware of the important role of perinatal autopsy in uncovering new information, or did not give the parents that piece of information.

When McHaffie compared the families who agreed to autopsy with those who refused, some interesting differences emerged, mainly relating to diagnosis, the doctor concerned, and the age of the child. Most children with a diagnosis of asphyxia or brain damage or congenital anomalies other than cardiac did have an autopsy. With a heart defect, only a third had an autopsy and this may reflect the belief that the diagnosis was already known from echocardiography. Most babies who died in the first day had an autopsy, as did those who died after three months. Between these times only about 50\% had an autopsy, and again this may reflect a belief that investigations had already given the diagnosis.

In all three units it was policy for the consultant to seek permission, and the rates of consent obtained varied widely, although specific details of each case are not given. However, it is clear that the approach of the person asking for consent is very important.

A survey of parental experience after loss of a pregnancy or a baby found that $5 \%$ of women who consented to autopsy, compared with 30\% who had not consented, subsequently regretted their decision. ${ }^{3}$ In McHaffie's study, no parent expressed such a regret when seen at 13 months, but doubt may not surface until future pregnancies, even those a generation later, and there is no available genetic baseline to guide decisions.

It is important that we continue to stress the importance of the perinatal autopsy and that we make sure that future neonatologists and obstetricians obtain the skills to ask for consent in a sensitive way that informs the parents adequately about the vital role of this investigation.

Arch Dis Child Fetal Neonatal Ed 2004;89:F284.

doi: 10.1136/adc.2003.037333

Correspondence to: Dr Lyon, Simpson Centre for Reproductive Health, Royal Infirmary of Edinburgh, Little France, Edinburgh EH16 4SA, Scotland, UK; andrew.lyon@luht.scot.nhs.uk

\section{REFERENCES}

1 Brodlie M, Laing IA, Keeling JW, et al. Ten years of neonatal autopsies in a tertiary referral centre: retrospective study. BMJ 2002;324:761-3.

2 McHaffie HE. Crucial decisions at the beginning of life. Oxford: Radcliffe Medical Press, 2001

3 Abdul RH, Khong TY. Perinatal infant postmortem examination. Survey of women's reactions to perinatal necropsy. BMJ 1995;310:870-1. 